\title{
Clima organizacional y su impacto en la calidad educativa universitaria
}

\section{Organizational climate and its impact on university educational quality}

Germán Martínez Prats. Universidad Juárez Autónoma de Tabasco, México. germanmtzprats@hotmail.com

Fabiola de Jesús Mapén Franco. Universidad Juárez Autónoma de Tabasco, México. mapenfranco@hotmail.com

Marynor Elena Ortega Ramírez. Universidad Autónoma de Chiapas, México. marynor.ortega@unach.mx

\section{RESUMEN.}

El compromiso social de las instituciones de educación superior de contribuir al desarrollo y bienestar de las sociedades lo cumple a través del perfil académico de sus egresados, lo cual implica la puesta en marcha de múltiples actividades inherentes a sus funciones sustantivas como la docencia e investigación pero también otras encaminadas a la evaluación a través de sus indicadores. Sin embargo, se reconoce que existen factores psicológicos y sociológicos que inciden en el comportamiento de los diversos agentes universitarios con la respectiva repercusión en la calidad educativa. Por ello, el objetivo de la presente investigación fue evaluar el clima organizacional en la Escuela Maya de Estudios Agropecuarios de la Universidad Autónoma de Chiapas en México y su impacto en el Sistema de Gestión de Calidad Institucional. La muestra para sustentar el estudio fue de 111 actores educativos. El enfoque de la investigación fue mixto y la validez de los instrumentos se realizó a través del Coeficiente Alfa de Cronbach cuyos resultados en las dimensiones de análisis oscilaron entre 0.898 y 0.95 . Los resultados reflejaron que los factores que afectan en mayor proporción el clima organizacional son: el confort, la motivación, identidad, comunicación, estructura, toma de decisiones, liderazgo, recompensa, innovación y cooperación en la solución de conflictos. El $24 \%$ considera que su contribución y labor de desempeño es valorada por todos los agentes educativos, mientras que el $48 \%$ considera que sus directivos carecen de capacidades gerenciales.

\section{PALABRAS CLAVE.}

Clima organizacional, Calidad Educativa, Educación Superior, Gestión educativa, Satisfacción alumnos.

\section{ABSTRACT.}

The social commitment of higher education institutions to contribute to the development and well-being of societies is fulfilled through the academic profile of its graduates, which implies the implementation of multiple activities inherent to their substantive functions such as

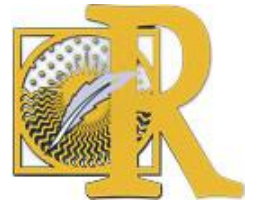

Fecha de recepción: 15-04-2020 Fecha de aceptación: 24-04-2020

Martínez Prats, G., Mapén Franco, F. J. \& Ortega Ramírez, M. E. (2021). Clima organizacional y su impacto en la calidad educativa universitaria. 
teaching and research but also others aimed at evaluation through its indicators. However, it is recognized that there are psychological and sociological factors that affect the behavior of the various university agents with the respective repercussion on educational quality. Therefore, the objective of this research was to evaluate the organizational climate at the Maya School of Agricultural Studies of the Autonomous University of Chiapas in Mexico and its impact on the Institutional Quality Management System. The sample to support the study was 111 educational actors. The research approach was mixed and the validity of the instruments was carried out through the Cronbach's Alpha Coefficient whose results in the analysis dimensions ranged between 0.898 and 0.95 . The results reflected that the factors that affect the organizational climate to a greater extent are: comfort, motivation, identity, communication, structure, decision-making, leadership, reward, innovation and cooperation in conflict resolution. $24 \%$ consider that their contribution and performance work is valued by all educational agents, while $48 \%$ consider that their managers lack managerial capacities.

\section{KEY WORDS.}

Organizational climate, Educational Quality, Higher Education, Educational management, Student satisfaction.

\section{Introducción.}

El clima organizacional es un filtro o fenómeno interviniente que media entre los factores del sistema organizacional (estructura, liderazgo, toma de decisiones) y las tendencias motivacionales que se traducen en un comportamiento que tiene consecuencias sobre la organización en cuanto a productividad, satisfacción, rotación, ausentismo, etc. Es el medio ambiente humano y físico, el conjunto de variables, cualidades, atributos o propiedades relativamente permanentes de un ambiente de trabajo concreto. Está relacionado con el comportamiento de las personas, su manera de trabajar y relacionarse, su interacción con la empresa, el liderazgo del directivo, las máquinas que se utilizan y la propia actividad de los trabajadores (Gonçalves, 2011). El clima en conjunto con las estructuras, descripciones de la organización y los recursos humanos que la conforman, crean un sistema interdependiente con alto nivel dinámico (Raymundo, Mapén y Martínez, 2019:4).

En este contexto, una preocupación fundamental en la que parecen haberse centrado los objetivos prioritarios de las organizaciones tanto públicas como privadas ha sido desarrollar mecanismos reductores de ansiedad que garanticen la preservación del equilibrio y la estabilidad de los sistemas formales, así como la construcción de significados compartidos que se reflejen en la conducta deseada de sus colaboradores.

Toda organización tiene características específicas que modelan el clima organizacional, siendo factores clave de la gestión, las acciones, el desempeño y los nuevos retos. Un elemento fundamental es el clima institucional, el cual repercute en las condiciones que lograrán el cumplimiento de los objetivos establecidos, es un factor determinante en la gestión educativa.

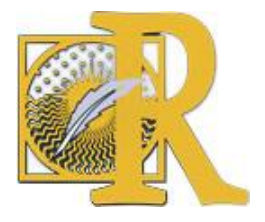

Fecha de recepción: 15-04-2020 Fecha de aceptación: 24-04-2020

Martínez Prats, G., Mapén Franco, F. J. \& Ortega Ramírez, M. E. (2021). Clima organizacional y su impacto en la calidad educativa universitaria. 
En el Programa Escuelas de Calidad-desde 2010-en México, se establece que la educación pública requiere propuestas innovadoras y eficaces que tengan un impacto positivo en el aprendizaje y en el logro académico de los estudiantes, así como en la Calidad Educativa; ideas que orienten e impulsen a los colectivos escolares para conocer nuevas maneras de hacer y lograr los propósitos de la educación, en relación con el perfil de egreso de sus alumnos. En este importante esfuerzo se propone que los profesores reorienten el modo en que llevan a cabo la gestión en la escuela y en el aula, con el fin de que coloquen en el centro de las decisiones el mejoramiento permanente del logro educativo de todos sus estudiantes. Por ello, surge la inquietud, de realizar una investigación, la cual enfocada a encontrar los principales aspectos que inciden en el clima organizacional en la Escuela Maya; lo cual se refleja en el incumplimiento de los objetivos y requisitos del Sistema de Gestión de Calidad a implantar afectando la productividad, la motivación, el desarrollo laboral y armonía de los integrantes que conforman la escuela. Es conveniente considerar, que a través del clima organizacional, se pueden rescatar valores y actitudes del ser humano, basados en el respeto, la aceptación y el reconocimiento de las capacidades individuales, mismas que fortalecen la unidad en toda organización; que en el caso de la Escuela Maya afectan directamente la Calidad Educativa y la mejora continua de los programas educativos que se imparten en la institución educativa.

Para ello, se evaluó el clima organizacional y su impacto en la calidad educativa considerando las relaciones interpersonales generadas en la Escuela Maya de Estudios Agropecuarios (EMEA) - es una unidad académica de educación superior pública dependiente de la Universidad Autónoma de Chiapas (UNACH) que genera, recrea y extiende el conocimiento; forma profesionales integrales con habilidades en su área de especialidad, con actitud crítica, propositiva, emprendedora, creativa, espíritu ético y humanista; para contribuir responsablemente en el desarrollo de la región, de Chiapas y de México con enfoque sustentable-, a través del análisis de regresión, a fin de determinar cuáles son las variables predictores que generan respuestas estadísticamente confiables al análisis de clima organizacional, Calidad Educativa basada en la Gestión Institucional y satisfacción de los estudiantes en la Escuela Maya, con lo cual se tendrá un modelo predictivo propuesto a partir del cual se deberán fundamentar los planes de trabajo propuestos para mejorar el clima organizacional y por ende, la Calidad Educativa. En general se podrá tener por primera vez, un panorama real de cómo se percibe la gestión institucional, su influencia en el clima laboral y la satisfacción de los estudiantes en la Escuela Maya de Estudios Agropecuarios. Al respecto, se elaboró un diagnóstico para evaluar el clima organizacional y como impacta en la calidad educativa, repercutiendo en la productividad y las relaciones interpersonales en la Escuela Maya de Estudios Agropecuarios, y en consecuencia, hacer una propuesta para cumplir eficientemente con los procesos y responder a las necesidades de los clientes y proveedores; considerando que las organizaciones para servir y desarrollarse, deben mantener un clima organizacional efectivo. Esta investigación, conlleva a crear conciencia sobre la situación que se desarrolla en la escuela Maya de estudios Agropecuarios en materia de clima organizacional, de comunicación, relaciones interpersonales, y el impacto en la Calidad Educativa basada en la Gestión Institucional y la satisfacción del estudiante. Es conveniente considerar, que, a través del clima organizacional, se pueden rescatar valores y

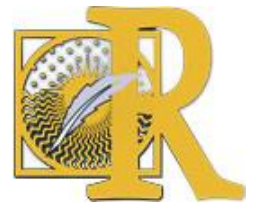

Fecha de recepción: 15-04-2020 Fecha de aceptación: 24-04-2020

Martínez Prats, G., Mapén Franco, F. J. \& Ortega Ramírez, M. E. (2021). Clima organizacional y su impacto en 
actitudes del ser humano, basados en el respeto, la aceptación y el reconocimiento de las capacidades individuales, mismas que fortalecen la unidad en toda organización; que en el caso de la Escuela Maya afectan directamente la Calidad Educativa y la mejora continua de los programas educativos que se imparten en esta casa de estudio.

Con este estudio se conocerán las oportunidades para mostrar habilidades que le ofrezcan un cierto grado de desafío al trabajador y que se incremente su interés por comprometerse al reto de la universidad. También, se beneficia a todo el sistema que opera en la Escuela Maya, sobre todo a nuestros clientes que son nuestros alumnos, seguido de los clientes en diversos procesos como académicos, administrativos y personal de confianza.

Esta investigación permitirá analizar los indicadores de Calidad Educativa basada en la Gestión Institucional y como estos deben ser recanalizados para mejorar la atención y calidad de servicio a los usuarios del sistema educativo de la escuela. En cuanto a la calidad fundamentada en la satisfacción al cliente (estudiante), se tendrán beneficios en la evaluación de las variables que generan impactos relevantes en la formación de los alumnos, permitiendo esto generar propuestas de trabajo que permitan atender las necesidades planteadas como muy importantes por los clientes. El proyecto permitirá evaluar los principales agentes que hacen que el clima organizacional se vea afectado en la Escuela Maya de estudios agropecuarios y repercuta en el incumplimiento de los requisitos de procesos del Sistema de Gestión de Calidad Institucional, enfocado a todo el personal que labora en este campus, tanto académicos, administrativos, personal obrero, de campo, así como alumnos. Con el objeto de analizar como el clima laboral ha afectado el proceso de Calidad Educativa, en el marco de iniciarse los procesos de acreditación de sus programas educativos. A través de los instrumentos aplicados, empleando el software SPSS, se determinarán los predictores que darán forma al modelo propuesto, para clima organizacional, y Calidad Educativa en la Escuela Maya de estudios agropecuarios. Así como la determinación de los principales agentes detonadores del clima laboral en esta institución.

\section{Desarrollo.}

Las universidades son concebidas como instituciones sociales que ejercen funciones estratégicas para el desarrollo cultural, científico y tecnológico y para los proyectos de consolidación de una sociedad.

En las universidades los estudiantes adquieren competencias, conocimientos y valores que les permitirán ejercer una adecuada toma de decisiones en su vida profesional y personal. Por lo tanto, los contenidos de las enseñanzas, los valores y las habilidades que se desarrollan en ellos han de ser pertinentes a las nuevas necesidades sociales. En este sentido, la pertinencia tendría que ser el principal criterio al momento de evaluar si las Instituciones de Educación Superior (IES) están cumpliendo su función social.

A lo largo de los años, las universidades se han ocupado de su pertinencia y su capacidad de respuesta ante la sociedad, y debido a esta inquietud los cambios sociales han incidido en la configuración de las instituciones de educación superior. Dicha pertinencia debe ser evaluada teniendo en cuenta las características principales de la institución: misión, objetivos y su organización, que a su vez deben ser congruentes con el contexto en el que se encuentran inmersas, siendo un factor determinante las particularidades - culturales y

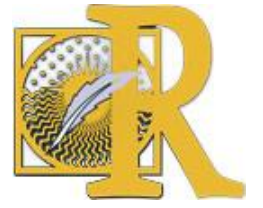

Fecha de recepción: 15-04-2020 Fecha de aceptación: 24-04-2020

Martínez Prats, G., Mapén Franco, F. J. \& Ortega Ramírez, M. E. (2021). Clima organizacional y su impacto en 
económicas- de sus estudiantes. Este primer análisis permite vincular la pertinencia con la calidad. Los esfuerzos encaminados a mejorar la calidad de la educación superior, como los sistemas de acreditación, no pueden ni deben omitir la valoración de su pertinencia.

La calidad, es entonces el resultado de un conjunto de acciones que responden a necesidades sociales determinadas que existen en un momento muy concreto. La calidad educativa, según Lafourcade (1988), puede significar la que posibilite el dominio de un saber desinteresado que se manifiesta en la adquisición de una cultura científica o literaria, la que desarrolla la máxima capacidad para generar riquezas o convertir a alguien en un recurso humano idóneo para contribuir al aparato productivo; la que promueve el suficiente espíritu crítico y fortalece el compromiso para transformar una realidad social enajenada por el imperio de una estructura de poder que beneficia socialmente a unos pocos. La calidad educativa, es una de las expresiones más utilizadas actualmente en el ámbito educativo, como punto de referencia que justifica cualquier proceso de cambio o plan de mejora. En este contexto, la eficacia y la eficiencia son sus dos pilares básicos. La calidad educativa, se entiende como un servicio que se presta a quienes se benefician de la misma. Lleva implícito dos conceptos básicos, los de eficacia (sirve para aquello para lo que fue realizado) y eficiencia (relación entre el costo y el resultado).Por otro lado, conviene recordar que calidad no es un concepto estático, es una característica de las cosas que indica perfeccionamiento, mejora, logro de metas. Calidad no es igual a perfección. Ninguna acción humana y, por lo tanto, ningún sistema educativo puede ser perfecto, pero sí debe aspirar a mejorar.

Si bien existe un conjunto de factores que influye en la calidad (los programas, los textos, la infraestructura, la formación de los profesores) ninguno de ellos ni todos juntos garantizan los resultados de la calidad; estos factores son sólo instrumentos y la calidad tiene que ver con un sistema de valores, ejercido por los principales actores: estudiantes y profesores, los padres y la propia sociedad. Calidad no se asocia sólo con contenidos o resultados en la educación; se propone definir la calidad de la educación no tanto en los fines sino en el proceso: educación de calidad, es aquella que llega a todas las personas que constituyen una sociedad. Calidad se asocia con eficiencia, medida ésta en términos de quién y cuántos tienen la oportunidad de acceso y permanencia a la educación (Álvarez, 1994). Por tanto, la acreditación con el fin de garantizar la calidad no puede basarse en un modelo único y universal, y no puede surgir tan sólo de la teoría y la abstracción, ni según tendencias del mercado. Todos estos procesos de la calidad dependen de múltiples factores, entre ellos, los procesos de interrelación personal y las actividades académicas y administrativas; lo cual redunda en el clima laboral. La discusión sobre el significado y la importancia de la calidad ha llevado a reconocer en la evaluación y en la acreditación los medios que puedan contribuir a una reforma de la educación superior, de manera que, además, se constituyan en los canales adecuados para comunicar a los usuarios de las instituciones, sobre los niveles alcanzados en las funciones básicas (docencia, investigación y difusión cultural) que desarrolla una institución universitaria. Evaluación y la acreditación no son fines en sí mismos; son medios para promover el mejoramiento de la educación superior. Hasta ahora ha resultado usual asociar ambas actividades con el mejoramiento de la calidad, la generación de información para la toma de decisiones, la garantía pública de la calidad de las instituciones y de los programas que ofrece. Adicionalmente a esto, han servido también

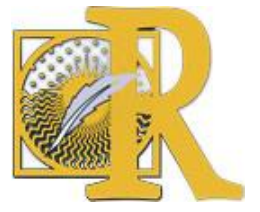

Fecha de recepción: 15-04-2020 Fecha de aceptación: 24-04-2020

Martínez Prats, G., Mapén Franco, F. J. \& Ortega Ramírez, M. E. (2021). Clima organizacional y su impacto en 
para garantizar la equivalencia y reconocimiento de títulos y grados en instituciones de un país o de varios (Pallan, 2004).

En los últimos años, los centros docentes han visto incrementado su grado de autonomía, especialmente en los ámbitos pedagógico y curricular, como factor esencial para elevar la calidad de la enseñanza que imparten. Es indudable que el incremento de medios personales y materiales ha de ir acompañado de una mayor capacidad para tomar iniciativas que permitan promover actuaciones innovadoras en aspectos pedagógicos, curriculares y organizativos. De esta forma, los procesos requieren una estructura que marque la razón de ser de la organización, no obstante la estructura no debe verse como algo fijo, sino que debe adecuarse a las necesidades de la organización, esto es el proceso requiere de la estructura como armazón específico, pero no de forma determinante, sino de forma flexible, adecuada a las necesidades, al entorno, a las sugerencias que los cambios van dictando, a las demandas que el personal de la organización va haciendo, y de acuerdo a las peculiaridades contextuales de la organización (Martínez y Rodriguez,2011).

El clima tiene una dependencia a las situaciones que se presenten en la institución, retoma elementos de la personalidad de los integrantes de la institución, está determinado por las características, las conductas, las actitudes, las aptitudes, el conocimiento, la motivación, las relaciones sociales entre los miembros de la institución (directivos, personal administrativo, docentes, estudiantes, padres de familia, comunidad), los valores, la cultura, las expectativas, el comportamiento y el tipo de Gestión que se realice en la institución, de forma que observar todos estos elementos permitirá un ambiente propicio para el cumplimiento de los objetivos. El clima, entonces, está representado por el ambiente interno existente entre el personal de la institución y que repercutirá en los factores externos y la Calidad Educativa, establecida como un elemento indispensable en la Reforma educativa mexicana.

Reddin (2004) enfatiza que el clima organizacional lo constituyen todos aquellos factores que influyen en la conducta de una organización o institución y que son comunes a puestos no necesariamente relacionados entre sí. En el Programa de Escuelas de Calidad es establece que la gestión debe dejar a un lado los usos y costumbres que propician la rutina y el aislamiento profesional. Lo que se propone es liderar procesos que aseguren los resultados; trabajar en equipo para asumir corresponsablemente las decisiones que llevan a lograr lo planeado, impulsar el involucramiento y la participación de los padres de familia, en la formación de sus hijos; evaluar el desempeño docente y el de los alumnos, con base en un enfoque de mejora continua. De lo que se trata es de entender, diseñar y ejecutar la planeación de la escuela y del aula de una manera totalmente renovada.

Como todo proceso de evaluación una de las limitantes más acentuadas es la actitud del personal docente, quienes en un primer momento se mostraron inconformes ante la aplicación de los instrumentos, por lo cual se contrató a una empresa externa especialista en aplicación de encuestas, para llevar a cabo el proceso.

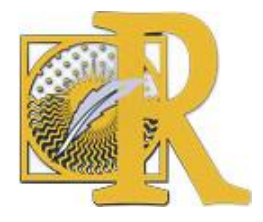

Fecha de recepción: 15-04-2020 Fecha de aceptación: 24-04-2020

Martínez Prats, G., Mapén Franco, F. J. \& Ortega Ramírez, M. E. (2021). Clima organizacional y su impacto en la calidad educativa universitaria. 


\section{Metodología.}

La presente investigación es de tipo descriptivo no experimental (Hernández, Fernández y Baptista, 2014) con enfoque cuantitativo, sin manipular las variables deliberadamente (Kerlinger y Lee, 2002). La recolección de datos se realizó a través de un cuestionario adaptado de Mendoza (2009) validado a través del juicio de seis expertos seleccionados de acuerdo a su trayectoria académica y experiencia en la investigación los ítems se diseñaron con una escala de Likert a fin de realizar un análisis de correlación entre las dimensiones y sus indicadores. La fiabilidad del instrumento se determinó a través del coeficiente alfa de Cronbach cuyos resultados en las dimensiones de análisis oscilaron entre 0.898 y 0.95 . Tal y como se muestran a continuación.

Tabla 1. Estadísticas de fiabilidad de los instrumentos aplicados para evaluar clima laboral y su impacto en la Calidad Educativa UNACH.

\begin{tabular}{|l|r|r|r|}
\hline \multicolumn{1}{|c|}{ Instrumento aplicado } & $\begin{array}{c}\text { Alfa de } \\
\text { Cronbach }\end{array}$ & $\begin{array}{c}\text { Alfa de Cronbach basada en } \\
\text { elementos estandarizados }\end{array}$ & N de elementos \\
\hline Satisfacción Al Cliente (Alumnos) & 0.951 & 0.951 & 45 \\
\hline Clima Organizacional & 0.951 & 0.948 & 37 \\
\hline Gestión Institucional & 0.898 & 0.908 & 27 \\
\hline
\end{tabular}

Nota: Elaboración propia.

La conceptualización de las variables, así como su operacionalización se presentan en las tablas siguientes.

Tabla 2. Conceptualización de las variables de investigación.

\begin{tabular}{|c|c|}
\hline $\begin{array}{c}\text { Variables } \\
\text { correlacionales }\end{array}$ & Conceptos \\
\hline $\begin{array}{l}\text { Clima organizacional } \\
\text { Robbins (2004); } \\
\text { Chiavenato (2006); } \\
\text { Goncalves (1997); } \\
\text { Reddin (2004) y } \\
\text { Brunet }(2011)\end{array}$ & $\begin{array}{l}\text { - Personalidad de la organización. } \\
\text { - Medio interno y la atmósfera de una organización. } \\
\text { - Fenómeno interviniente que media entre los factores de la organización. } \\
\text { - Propiedad del individuo que percibe la organización. } \\
\text { - Constituyen todos aquellos factores que influyen en la conducta de una } \\
\text { organización. } \\
\text { - Conjunto de características que son percibidas de una organización. }\end{array}$ \\
\hline $\begin{array}{l}\text { Calidad Educativa } \\
\text { Álvarez (1994) } \\
\text { Lafourcade (1998) }\end{array}$ & $\begin{array}{l}\text { - Proceso de gestión en el que se debe dejar a un lado los usos y } \\
\text { costumbres que propician la rutina y el aislamiento profesional. } \\
\text { - Una de las expresiones más utilizadas actualmente en el ámbito educativo, } \\
\text { como punto de referencia que justifica cualquier proceso de cambio o plan } \\
\text { de mejora. } \\
\text { - Significa investigar, formar profesores y documentarlos. Si bien existe un } \\
\text { conjunto de factores que influye en la calidad. } \\
\text { - Formulado a la luz de la apreciación del educando y sólo puede definirse } \\
\text { con base en las especificaciones que satisfagan sus exigencias. } \\
\text { - Educación es un servicio que se considera de calidad cuando logra la } \\
\text { satisfacción del estudiante. }\end{array}$ \\
\hline
\end{tabular}

Nota: elaboración propia con base en los autores que se mencionan.

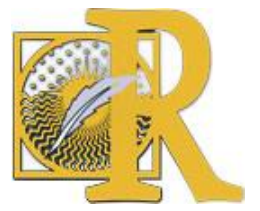

Fecha de recepción: 15-04-2020 Fecha de aceptación: 24-04-2020

Martínez Prats, G., Mapén Franco, F. J. \& Ortega Ramírez, M. E. (2021). Clima organizacional y su impacto en la calidad educativa universitaria. 
Tabla 3. Operacionalización de la variable independiente: Clima Organizacional

\begin{tabular}{|c|c|c|c|}
\hline $\begin{array}{l}\text { Variables } \\
\text { correlacionales }\end{array}$ & Dimensiones & Indicadores & Ítems \\
\hline \multirow{10}{*}{ Clima organizacional } & \multirow[t]{4}{*}{ Potencial humano } & Liderazgo & 3 \\
\hline & & Innovación & 4 \\
\hline & & Recompensa & 3 \\
\hline & & Confort & 3 \\
\hline & \multirow[t]{3}{*}{ Diseño organizacional } & Estructura & 1 \\
\hline & & Toma de decisiones & 3 \\
\hline & & Comunicación organizacional & 4 \\
\hline & \multirow[t]{3}{*}{ Cultura de la organización } & Identidad & 2 \\
\hline & & Conflicto y cooperación & 5 \\
\hline & & Motivación & 2 \\
\hline
\end{tabular}

Nota: elaboración propia.

Tabla 4. Variable: Calidad Educativa (satisfacción al cliente y gestión institucional).

\begin{tabular}{|c|c|c|c|}
\hline Variable & Dimensiones & Indicadores & \\
\hline & $\begin{array}{l}\text { Satisfacción del } \\
\text { alumno - } \\
\text { Sección A: } \\
\text { Importancia }\end{array}$ & $\begin{array}{l}\text { - Los que influyen en el desempeño académico del } \\
\text { estudiante: } \\
\text { Gestión de directivos, Actividades académicas y } \\
\text { extracurriculares, Infraestructura disponible, Servicios } \\
\text { informativos, asistenciales, culturales y deportivos, } \\
\text { Desempeño de los profesores, Servicio de tutorías, } \\
\text { Relaciones con tus compañeros, Evaluación del } \\
\text { rendimiento académico, Actividades prácticas y/o campo y } \\
\text { Competencias profesionales adquiridas. }\end{array}$ & 10 \\
\hline & $\begin{array}{l}\text { Satisfacción del } \\
\text { alumno- } \\
\text { Sección B: } \\
\text { Satisfacción }\end{array}$ & $\begin{array}{l}\text {-Satisfacción del alumno con la atención de los directivos } \\
\text {-Satisfacción del alumno con las actividades académicas } \\
\text { extracurriculares } \\
\text {-Satisfacción del alumno con la infraestructura disponible } \\
\text {-Satisfacción del alumno con los servicios informativos, } \\
\text { asistenciales, culturales y deportivos } \\
\text {-Satisfacción del alumno con el desempeño de sus } \\
\text { profesores } \\
\text {-Satisfacción del alumno con el servicio de tutorías } \\
\text {-Satisfacción del alumno con sus compañeros } \\
\text {-Satisfacción del alumno con la evaluación de su rendimiento } \\
\text { académico } \\
\text {-Satisfacción del alumno con el desarrollo de actividades } \\
\text { prácticas y/o campo } \\
\text {-Satisfacción del alumno con sus Competencias } \\
\text { profesionales }\end{array}$ & $\begin{array}{l}4 \\
3 \\
5 \\
6 \\
6 \\
3 \\
2 \\
2 \\
3 \\
1\end{array}$ \\
\hline
\end{tabular}

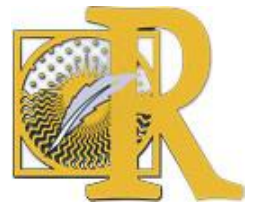

Fecha de recepción: 15-04-2020 Fecha de aceptación: 24-04-2020

Martínez Prats, G., Mapén Franco, F. J. \& Ortega Ramírez, M. E. (2021). Clima organizacional y su impacto en la calidad educativa universitaria. 


\begin{tabular}{|c|c|c|c|}
\hline $\begin{array}{c}\text { Calidad } \\
\text { Educativa }\end{array}$ & $\begin{array}{l}\text { Gestión } \\
\text { Institucional }\end{array}$ & $\begin{array}{l}\text {-Visión-misión } \\
\text {-Objetivos-metas } \\
\text {-Estrategias y políticas } \\
\text {-Estructura orgánica } \\
\text {-Comportamiento organizacional } \\
\text {-Estructura social } \\
\text {-Liderazgo } \\
\text {-Trabajo en equipo } \\
\text {-Toma de decisiones } \\
\text {-Competencia } \\
\text {-Proceso de control } \\
\text {-Innovación } \\
\text {-Presión en el trabajo } \\
\text {-Condiciones de trabajo } \\
\text {-Recompensa- reconocimiento } \\
\text {-Responsabilidad } \\
\text {-Cordialidad } \\
\text {-Identidad } \\
\text {-Comunicación } \\
\text {-Comunicación interpersonal } \\
\text {-Ambiente de trabajo } \\
\text {-Satisfacción personal } \\
\text {-Valores } \\
\text {-Actitud de los usuarios }\end{array}$ & $\begin{array}{l}1 \\
1 \\
1 \\
1 \\
1 \\
1 \\
1 \\
1 \\
1 \\
1 \\
1 \\
1 \\
1 \\
1 \\
1 \\
1 \\
1 \\
1 \\
1 \\
2 \\
1 \\
1 \\
1 \\
1\end{array}$ \\
\hline
\end{tabular}

Nota: elaboración propia.

Para determinar la muestra se estableció un índice de confianza de hasta $90 \%$, es decir, solo se acepta $10 \%$ de error. El tamaño de la muestra se calculó con la siguiente fórmula (Münch y Ángeles, 1990: p.32), cuyos resultados se muestran en la Tabla 5:

$$
n=\frac{k^{\wedge} 2 * p^{*} q^{*} N}{\left(e^{\wedge 2 *}(N-1)\right)+k^{\wedge} 2 * p^{*} q}
$$

$\mathrm{N}$ : es el tamaño de la población o universo (número total de posibles encuestados).

k: es una constante que depende del nivel de confianza que se asigne. Para este caso se aplicó un $90 \%$.

e: es el error muestral deseado. Se consideró un $10 \%$.

p: es la proporción de individuos que poseen en la población la característica de estudio. Se consideró 0.5

q: es la proporción de individuos que no poseen esa característica, por lo tanto, para este caso es 0.5

n: es el tamaño de la muestra (número de encuestas que se van a aplicar).

La muestra para cada uno de los sujetos de estudio quedó de la siguiente manera:

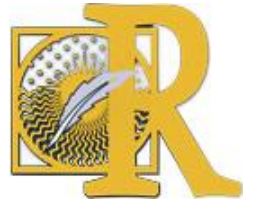

Fecha de recepción: 15-04-2020 Fecha de aceptación: 24-04-2020

Martínez Prats, G., Mapén Franco, F. J. \& Ortega Ramírez, M. E. (2021). Clima organizacional y su impacto en la calidad educativa universitaria. 
Tabla 5. Resultados del Cálculo del Tamaño de la muestra.

\begin{tabular}{|l|c|c|c|}
\hline \multicolumn{1}{|c|}{ Sujetos de estudio } & Población & Muestra calculada & Muestra aplicada \\
\hline Alumnos & 173 & 49 & 50 \\
\hline Docentes & 44 & 27 & 30 \\
\hline $\begin{array}{l}\text { Administrativos y Directivos } \\
\text { (Algunos docentes cumplen } \\
\text { funciones administrativas) }\end{array}$ & 45 & 27 & \\
\hline
\end{tabular}

Nota: Elaboración propia.

\section{Resultados.}

Para analizar los resultados, se parte de la idea que debe existir una relación entre las diversas dimensiones del clima organizacional sobre la gestión de la Calidad Educativa, estableciéndose una interdependencia entre ellas y no actuando en forma individual, estos resultados son evidentes bajo el análisis del modelo de regresión lineal múltiple.

En la siguiente tabla se muestran los valores de $\mathrm{F}$ y su significancia para las variables medidas en el análisis de clima organizacional y su impacto en la Calidad Educativa de la EMEA- UNACH; donde se observa que existen diferenciales altamente significativas entre los predictores o variables que constituyen el análisis.

Tabla 6. Valores de F y su significancia para las variables medidas en el análisis de clima organizacional y su impacto en la Calidad Educativa de la EMEA- UNACH.

\begin{tabular}{|l|c|c|c|c|c|}
\hline \multicolumn{1}{|c|}{ Factor de variación } & $\begin{array}{c}\text { Suma de } \\
\text { cuadrados }\end{array}$ & gl & Media cuadrática & $\mathbf{F}$ & Sig. \\
\hline Clima organizacional & 13.361 & 10 & 1.336 & 13.400 & $0.0001^{\mathrm{b}}$ \\
\hline $\begin{array}{l}\text { Calidad Educativa } \\
\text { basada en la Gestión } \\
\text { Institucional }\end{array}$ & 9.064 & 16 & 0.566 & 54.115 & $0.0005^{\mathrm{b}}$ \\
\hline $\begin{array}{l}\text { Calidad Educativa } \\
\text { basada en Satisfacción } \\
\text { al cliente }\end{array}$ & 31.523 & 11 & 2.866 & 31.505 & $0.0008^{\mathrm{b}}$ \\
\hline
\end{tabular}

Nota: elaboración propia con base a resultados de investigación. 
Tabla 7. Resultados de Correlación (Rho de Spearman) para las variables medidas para clima organizacional.

\begin{tabular}{|c|c|c|c|c|c|c|c|c|c|c|}
\hline \multicolumn{11}{|c|}{ Correlaciones } \\
\hline & MOT & LIDERAZGO & $\begin{array}{c}\text { TOMA } \\
\text { DE } \\
\text { DECISI } \\
\text { ONES }\end{array}$ & $\begin{array}{c}\text { IDENTI } \\
\text { DAD } \\
\end{array}$ & $\begin{array}{l}\text { COMUNIC } \\
\text { ACION }\end{array}$ & $\begin{array}{l}\text { ESTRUC } \\
\text { TURA }\end{array}$ & $\begin{array}{l}\text { INNOVA } \\
\text { CION }\end{array}$ & $\begin{array}{c}\text { CONFLICTO } \\
\text { COOPE }\end{array}$ & $\begin{array}{c}\text { RECOMPEN } \\
\text { SA }\end{array}$ & CONFORT \\
\hline MOTIVACIÓN & 1 & $.371^{*}$ & .207 & .168 & .272 & $.410^{*}$ & 231 & .109 & $.497^{* *}$ & .226 \\
\hline LIDERAZGO & $.371^{*}$ & 1 & $.649^{* *}$ & 193 & $.649^{* *}$ & $.513^{* *}$ & $.613^{* *}$ & $.595^{* *}$ & $.699^{* *}$ & $618^{* *}$ \\
\hline $\begin{array}{l}\text { TOMA DE } \\
\text { DECISIONES }\end{array}$ & .207 & $.649^{* *}$ & 1 & $.337^{*}$ & $.698^{* *}$ & $.537^{* *}$ & $.685^{* *}$ & $.475^{* *}$ & $.495^{* *}$ & $.575^{* *}$ \\
\hline IDENTIDAD & .168 & .193 & $.337^{*}$ & 1 & $.419^{* *}$ & $.347^{*}$ & .213 & .205 & .237 & $.507^{* *}$ \\
\hline COMUNICACION & .272 & .649** & $.698^{* *}$ & $.419^{* *}$ & 1 & $.599^{* *}$ & $.649^{* *}$ & $.723^{* *}$ & $.575^{* *}$ & $.529^{* *}$ \\
\hline ESTRUCTURA & $.410^{*}$ & $.513^{* *}$ & $.537^{* *}$ & $.347^{*}$ & $.599^{* *}$ & 1 & $.655^{* *}$ & $.539^{* *}$ & $.634^{* *}$ & $.496 *$ \\
\hline INNOVACION & .231 & $.613^{* *}$ & $.685^{* *}$ & .213 & $.649^{* *}$ & $.655^{* *}$ & 1 & $.658^{* *}$ & $.557^{* *}$ & $628^{* *}$ \\
\hline CONFLICTOCOOPE & .109 & $.595^{* *}$ & $.475^{* *}$ & 205 & $.723^{* *}$ & $.539^{* *}$ & $.658^{* *}$ & 1 & $.658^{* *}$ & $.710^{* *}$ \\
\hline RECOMPENSA & $.497^{*}$ & .699** & $.495^{* *}$ & 237 & $.575^{* *}$ & $.634^{* *}$ & $.557^{* *}$ & $.658^{* *}$ & 1 & $.627^{* *}$ \\
\hline CONFORT & .226 & $.618^{* *}$ & $.575^{* *}$ & $.507^{* *}$ & $.529^{* *}$ & $.496^{* *}$ & $.628^{* *}$ & $.710^{* *}$ & $.627^{* *}$ & 1 \\
\hline
\end{tabular}

Tabla 8. Análisis de la Varianza para las variables medidas para clima organizacional

\begin{tabular}{|l|c|c|c|c|}
\hline \multicolumn{1}{|c|}{ Variables medidas } & Suma de cuadrados & Media cuadrática & F & Sig. \\
\hline Motivación1 & .755 & .755 & 1.076 & .308 \\
\hline Motivación2 & .050 & .050 & .037 & .849 \\
\hline Liderazgo3 & 3.143 & 3.143 & 2.495 & .125 \\
\hline Liderazgo4 & 3.355 & 3.355 & 1.871 & .182 \\
\hline Liderazgo5 & 1.578 & 1.578 & 1.041 & .316 \\
\hline Liderazgo6 & 2.439 & 2.439 & 1.495 & .231 \\
\hline Tomadecisión7 & 2.780 & 2.780 & 1.745 & .197 \\
\hline Tomadecisión8 & .387 & .387 & .285 & .597 \\
\hline Tomadecisión9 & .011 & .011 & .006 & .939 \\
\hline Identidad10 & .496 & .496 & 2.923 & .098 \\
\hline Identidad11 & .100 & .100 & .252 & .620 \\
\hline Identidad12 & .005 & .005 & .008 & .931 \\
\hline Identidad13 & .417 & .417 & .378 & .543 \\
\hline Comunicación14 & .305 & .305 & .156 & .696 \\
\hline Comunicación15 & .189 & .189 & .087 & .770 \\
\hline Comunicación16 & .305 & .305 & .151 & .701 \\
\hline
\end{tabular}

Fecha de recepción: 15-04-2020 Fecha de aceptación: 24-04-2020

Martínez Prats, G., Mapén Franco, F. J. \& Ortega Ramírez, M. E. (2021). Clima organizacional y su impacto en la calidad educativa universitaria. 


\begin{tabular}{|l|c|c|c|c|}
\hline \multicolumn{1}{|c|}{ Variables medidas } & Suma de cuadrados & Media cuadrática & F & Sig. \\
\hline Comunicación17 & 1.043 & 1.043 & 1.275 & .268 \\
\hline Estructura18 & .040 & .040 & .031 & .862 \\
\hline Estructura19 & .150 & .150 & .101 & .753 \\
\hline Estructura20 & .009 & .009 & .012 & .912 \\
\hline Estructura21 & .221 & .221 & .191 & .665 \\
\hline Innovación22 & 1.092 & 1.092 & .560 & .460 \\
\hline Innovación23 & 2.259 & 2.259 & 1.581 & .219 \\
\hline Innovación24 & .927 & .927 & .572 & .456 \\
\hline Innovación25 & .124 & .124 & .087 & .770 \\
\hline Conflictocooperación26 & .179 & .179 & .096 & .758 \\
\hline Conflictocooperación27 & .619 & .619 & .397 & .534 \\
\hline Conflictocooperación28 & .950 & .950 & .715 & .405 \\
\hline Conflictocooperación29 & .232 & .232 & .136 & .715 \\
\hline Conflictocooperación30 & 3.227 & 3.227 & 2.118 & .156 \\
\hline Recompensa31 & .141 & .141 & .193 & .664 \\
\hline Recompensa32 & .159 & .159 & .105 & .748 \\
\hline Recompensa33 & 2.859 & 2.859 & 1.761 & .195 \\
\hline Confort34 & .480 & .480 & .334 & .568 \\
\hline Confort35 & 1.491 & 1.491 & .857 & .362 \\
\hline Confort36 & .045 & .045 & .028 & .869 \\
\hline Confort37 & .619 & .619 & .364 & .551 \\
\hline Nota: & & & & \\
\hline
\end{tabular}

Nota: elaboración propia con base a los resultados de investigación.

En la siguiente tabla se presenta el análisis de correlación entre las variables medidas para Calidad Educativa basada en la gestión institucional, en donde se puede constatar que las variables con mayor índice de correlación son liderazgo vs comportamiento organizacional con probabilidad de 0,743; seguido de cordialidad con 0,711. Siendo éstas las que presentan correlación más cercana a 1. 
Tabla 9. Análisis de correlación entre las variables medidas para Calidad Educativa basada en la gestión institucional.

\begin{tabular}{|c|c|c|c|c|c|c|c|c|c|c|c|c|c|c|c|c|c|c|c|c|c|c|c|c|c|c|c|}
\hline \multicolumn{28}{|c|}{ Correlaciones } \\
\hline & & $\begin{array}{l}\text { OBJE } \\
\text { TIVOS }\end{array}$ & $\begin{array}{l}\text { EST } \\
\text { RET }\end{array}$ & $\begin{array}{l}\text { ESTR } \\
\text { UCTU }\end{array}$ & $\begin{array}{l}\text { COMPO } \\
\text { RTAMIE }\end{array}$ & ESTRU & \begin{tabular}{l|l} 
LID \\
ER
\end{tabular} & TRABA & $\begin{array}{l}\text { TOMAD } \\
\text { EDESI }\end{array}$ & $\begin{array}{l}\text { COM } \\
\text { PET }\end{array}$ & $\begin{array}{l}\text { PROCE } \\
\text { SOSDE }\end{array}$ & $\begin{array}{l}\text { INN } \\
\text { OVA }\end{array}$ & \begin{tabular}{l|}
$\mathrm{PR}$ \\
$\mathrm{ES}$
\end{tabular} & COND & $\begin{array}{l}\text { REC } \\
\text { OMP }\end{array}$ & $\begin{array}{l}\text { RESP } \\
\text { ONSA }\end{array}$ & $\mathrm{COR}$ & $\begin{array}{l}\text { IDE } \\
\text { NTI }\end{array}$ & $\begin{array}{l}\text { COM } \\
\text { UNIC }\end{array}$ & \begin{tabular}{l|l} 
CO \\
MIN
\end{tabular} & $\begin{array}{l}\mathrm{CO} \\
\mathrm{MUI}\end{array}$ & $\begin{array}{l}\text { COM } \\
\text { UNCI }\end{array}$ & MBIE & $\begin{array}{l}\text { SATISFA } \\
\text { CCIONP }\end{array}$ & $\begin{array}{l}\text { VA } \\
\text { LO }\end{array}$ & $\begin{array}{l}\text { ACTIT } \\
\text { UDUS }\end{array}$ & GES \\
\hline & VISIC & META & GIA & RAOR & NTOOR & CTURA & $A Z$ & JOENE & CIONE & ENCI & CONTR & $\mathrm{ClO}$ & 10 & ICTRA & ENS & BILIDA & DIAL & $\mathrm{DA}$ & $\mathrm{ACIO}$ & TER & NTE & NTER & NTETR & ERSONA & RE & UARIO & TION \\
\hline & $\mathrm{SIC}$ & & & & $\mathrm{G}$ & SOCIAL & GO & QUIPO & $\mathrm{s}$ & A & $\mathrm{OL}$ & $\mathrm{N}$ & $\mathrm{N}$ & BAJO & A & $\mathrm{D}$ & IDAD & $\mathrm{D}$ & $\mathrm{N}$ & 1 & $\mathrm{R} 2$ & 3 & ABAJO & 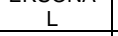 & $\mathrm{s}$ & $\mathrm{s}$ & INST \\
\hline VISIONMISION & 1 & $.488^{\prime \prime}$ & .007 & -.138 & -.145 & .117 & .128 & .116 & -.044 & -.246 & -.167 & .068 & \begin{tabular}{r|}
.26 \\
4
\end{tabular} & -.107 & -.053 & .027 & $336^{\circ}$ & $\begin{array}{r}.07 \\
3\end{array}$ & -.238 & 111 & .238 & -.054 & 017 & 287 & \begin{tabular}{r|r}
.00 \\
0
\end{tabular} & .155 & .089 \\
\hline OBJETIVOSMETAS & $.488^{\prime \prime}$ & 1 & $.556^{\circ}$ & $.321^{\circ}$ & $.377^{\circ}$ & $.333^{*}$ & .354 & .444"* & 208 & 287 & .165 & .121 & $\begin{array}{l}.32 \\
\end{array}$ & .247 & .123 & $.408^{*}$ & 237 & $\begin{array}{l}39 \\
.39\end{array}$ & .251 & .250 & $.361^{\circ}$ & 176 & .115 & 261 & .12 & $.361^{*}$ & $.497^{*}$ \\
\hline ESTRETGIAS & .007 & $.556 *$ & 1 & $600^{\prime \prime}$ & $.577^{* *}$ & $.479^{* *}$ & .482 & $.526^{*+}$ & $.378^{\circ}$ & $.414^{*}$ & $.451^{*}$ & $.396^{*}$ & $\begin{array}{r}1 \\
.25 \\
7\end{array}$ & $.577^{* *}$ & $.533^{*}$ & $.661^{\prime \prime}$ & $.549^{\circ}$ & $\begin{array}{r}.24 \\
2 \\
\end{array}$ & $.363^{*}$ & .349 & $.320^{\circ}$ & .087 & 258 & $.392^{\circ}$ & $\begin{array}{r}22 \\
.22 \\
\end{array}$ & $.436^{\prime \prime}$ & $.609^{* *}$ \\
\hline ESTRUCTURAORG & -.138 & $.321^{*}$ & $.600^{\circ}$ & 1 & $.636^{* \prime}$ & $.538^{* \prime}$ & .512 & $442^{*+}$ & .087 & $.354^{*}$ & $.534^{* \prime}$ & $.400^{\circ}$ & \begin{tabular}{r|r}
.05 \\
2
\end{tabular} & $.353^{\circ}$ & $.385^{\circ}$ & $647^{\prime \prime}$ & $.659^{\circ}$ & $\begin{array}{r}.27 \\
9\end{array}$ & .249 & .391 & .283 & .155 & $.372^{\circ}$ & $.497^{* *}$ & \begin{tabular}{r|r}
.00 \\
0
\end{tabular} & $.396^{\circ}$ & $.587^{* *}$ \\
\hline COMPORTAMIENTOORG & -.145 & $.377^{*}$ & $.577^{\circ}$ & .636" & 1 & $.593^{* *}$ & .743 & $.636^{*}$ & 249 & $.568^{*}$ & $.567^{\prime \prime}$ & $.598^{\prime \prime}$ & \begin{tabular}{r|r|}
.06 \\
5
\end{tabular} & $.529^{* \prime}$ & $.574^{* 1}$ & $.566^{\prime \prime}$ & .711 & $\begin{array}{r}20 \\
1\end{array}$ & 244 & 340 & $.385^{\circ}$ & .055 & $.549^{\prime \prime}$ & $.565^{* 1}$ & \begin{tabular}{r|r}
.17 \\
3
\end{tabular} & $680 "$ & $.627^{*}$ \\
\hline ESTRUCTURASOCIAL & 117 & $.333^{*}$ & $.479^{\circ}$ & $.538^{\prime \prime}$ & $.593^{*}$ & 1 & .682 & $.563^{* *}$ & .208 & $.618^{* *}$ & $.659^{* \prime}$ & $.700^{*}$ & \begin{tabular}{c|c}
.07 \\
0
\end{tabular} & $.336^{\circ}$ & $.549^{* *}$ & .639" & .304 & .51 & $.459^{* \prime}$ & .370 & $.427^{\circ}$ & 240 & .304 & $.528^{* 1}$ & .10 & $.631^{\prime \prime}$ & $.740^{\circ *}$ \\
\hline LIDER & .128 & $.354^{*}$ & $.482^{\circ}$ & $.512^{* 1}$ & $.743^{* \prime}$ & .682 & 1 & $.843^{* *}$ & $.404^{*}$ & $.540^{* *}$ & $.525^{\prime \prime}$ & $.649^{*}$ & $\begin{array}{r}.09 \\
6\end{array}$ & $.433^{* *}$ & $.557^{*}$ & $.586 "$ & $.535^{\circ}$ & $\begin{array}{r}0 \\
.27 \\
7\end{array}$ & .159 & .482 & $.686^{\circ}$ & .193 & $.609^{*}$ & $.696^{*}$ & $\begin{array}{r}1 \\
.23 \\
9\end{array}$ & $.675^{*}$ & $.712^{* *}$ \\
\hline TRABAJOENEQUIPO & .116 & $.444^{*+}$ & $.526^{\circ}$ & $.442^{\prime \prime}$ & $.636^{* \prime}$ & $.563^{* *}$ & 843 & 1 & $.554^{\prime \prime}$ & $.563^{* *}$ & $.548^{\prime \prime}$ & $.507^{\circ}$. & $\begin{array}{r}.23 \\
0\end{array}$ & $.517^{* \prime}$ & $.582^{* \prime}$ & $.694^{\prime \prime}$ & $.473^{\circ}$ & $\begin{array}{c}.37 \\
2^{*}\end{array}$ & .267 & 617 & $.520^{\circ}$ & 131 & $.645^{\prime \prime}$ & $.632^{* *}$ & \begin{tabular}{r|r}
.20 \\
6
\end{tabular} & $.589^{\prime \prime}$ & $.695^{* *}$ \\
\hline TOMADEDESICIONES & -.044 & 208 & $.378^{\circ}$ & .087 & .249 & 208 & .404 & $.554^{*}$ & 1 & $.465^{*}$ & $.369^{\circ}$ & $.350^{\circ}$ & \begin{tabular}{r|r}
.20 \\
1
\end{tabular} & $.571^{\prime \prime}$ & .283 & $.373^{\circ}$ & .186 & $\begin{array}{r}.09 \\
9\end{array}$ & $.419^{\circ}$ & .465 & $.431^{\circ}$ & -.288 & $.421^{\circ}$ & .081 & $\begin{array}{c}.40 \\
5\end{array}$ & .262 & $.525^{*}$ \\
\hline COM & -.246 & 287 & $.414^{*}$ & $.354^{\circ}$ & $.568^{\prime \prime}$ & $.618^{* \prime}$ & 540 & $.563^{*}$ & $.465^{\prime \prime}$ & 1 & $.630^{\circ \prime}$ & $.536^{*}$ & $\begin{array}{r}.01 \\
6\end{array}$ & $.441^{* \prime}$ & $.438^{* 1}$ & $.550^{\circ \prime}$ & $.471^{*}$ & $\begin{array}{c}.34 \\
9^{\circ}\end{array}$ & $.668^{\prime \prime}$ & .470 & $.371^{\circ}$ & 193 & $.332^{*}$ & $.336^{\circ}$ & $\begin{array}{r}.11 \\
9\end{array}$ & $.354^{*}$ & $.629^{*}$ \\
\hline PROCESOSDECONTROL & -.167 & .165 & $.451^{*}$ & $.534^{\prime \prime}$ & $.567^{*}$ & $.659^{\prime \prime}$ & .525 & $.548^{* *}$ & $.369^{\circ}$ & $.630^{*}$ & 1 & $.562^{*}$ & $\begin{array}{r}. \\
.10 \\
2\end{array}$ & $.520^{* *}$ & $.352^{*}$ & $.625^{\prime \prime}(x-1)$ & $.435^{*}$ & $\begin{array}{c}.36 \\
2^{\circ}\end{array}$ & $.524^{* \prime}$ & .480 & .103 & .175 & $.564^{\prime \prime}$ & $.334^{\circ}$ & $\begin{array}{r}.10 \\
5 \\
\end{array}$ & $.605 "$ & $.570^{\circ *}$ \\
\hline INNOVACION & .068 & .121 & $.396^{\circ}$ & $.400^{\circ}$ & $.598^{* \prime}$ & $.700^{* *}$ & .649 & $.507^{* *}$ & $.350^{\circ}$ & $.536^{* \prime}$ & $.562^{\prime \prime}$ & 1 & $\begin{array}{r}.09 \\
4\end{array}$ & $.503^{* \prime}$ & $.549^{* \prime}$ & $.477^{\prime \prime}$ & $.487^{\circ}$ & $\begin{array}{r}.27 \\
5\end{array}$ & $318^{\circ}$ & .276 & $.402^{\circ}$ & -.011 & $.515^{\prime \prime}$ & $.521^{* \prime}$ & \begin{tabular}{r|r}
.09 \\
0
\end{tabular} & $619^{\prime \prime}$ & $.667^{* *}$ \\
\hline PRESION & .264 & $321^{*}$ & .257 & .052 & .065 & .070 & .096 & .230 & .201 & -.016 & -.102 & .094 & 1 & .181 & .282 & .248 & .109 & $\begin{array}{r}.04 \\
8\end{array}$ & .018 & .093 & .091 & .237 & .064 & .039 & .01 & -.062 & $322^{*}$ \\
\hline CONDICTRABAJO & -.107 & .247 & $.577^{\circ}$ & $.353^{*}$ & $.529^{*}$ & $.336^{*}$ & .433 & $.517^{* *}$ & $.571^{\prime \prime}$ & $.441^{* *}$ & $.520 *$ & $.503^{\circ}$ & $\begin{array}{r}.18 \\
1\end{array}$ & 1 & .262 & $.327^{*}$ & $.491^{\circ}$ & $\begin{array}{r}.07 \\
7 \\
\end{array}$ & $.392^{\circ}$ & .416 & .274 & -.186 & $.505^{* \prime}$ & .197 & $\begin{array}{r}.28 \\
4 \\
\end{array}$ & $.344^{*}$ & $.562^{* *}$ \\
\hline RECOMPENSA & -.053 & .123 & $.533^{\circ}$ & $.385^{\circ}$ & $.574^{*}$ & $.549^{* *}$ & .557 & $.582^{* *}$ & .283 & $.438^{* *}$ & $.352^{\circ}$ & $.549^{\prime}$ & $\begin{array}{r}.28 \\
2 \\
\end{array}$ & .262 & 1 & $.587^{\prime \prime}$ & $.335^{\circ}$ & $\begin{array}{r}.28 \\
4 \\
\end{array}$ & .213 & .112 & .301 & .164 & 207 & $.630^{\circ *}$ & $\begin{array}{r}.08 \\
6 \\
\end{array}$ & $.400^{\circ}$ & $.570^{* *}$ \\
\hline
\end{tabular}




Continuación Tabla 9. Análisis de correlación entre las variables medidas para Calidad Educativa basada en la gestión institucional.

\begin{tabular}{|c|c|c|c|c|c|c|c|c|c|c|c|c|c|c|c|c|c|c|c|c|c|c|c|c|c|c|c|}
\hline \multicolumn{28}{|c|}{ Correlaciones } \\
\hline & $\begin{array}{c}\text { VISIONMI } \\
\text { SION }\end{array}$ & $\begin{array}{l}\text { OBJE } \\
\text { TIVOS } \\
\text { META } \\
\text { S }\end{array}$ & \begin{tabular}{|c|} 
EST \\
RET \\
GIA \\
S \\
\end{tabular} & $\begin{array}{l}\text { ESTR } \\
\text { UCTU } \\
\text { RAOR } \\
\text { G }\end{array}$ & $\begin{array}{c}\text { COMPO } \\
\text { RTAMIE } \\
\text { NTOOR } \\
\text { G } \\
\end{array}$ & $\begin{array}{l}\text { ESTRU } \\
\text { CTURA } \\
\text { SOCIAL }\end{array}$ & $\begin{array}{l}\text { LID } \\
E R \\
A Z \\
G O \\
\end{array}$ & $\begin{array}{l}\text { TRABA } \\
\text { JOENE } \\
\text { QUIPO } \\
\end{array}$ & \begin{tabular}{c|} 
TOMAD \\
EDESI \\
CIONE \\
$S$ \\
\end{tabular} & $\begin{array}{l}\text { COM } \\
\text { PET } \\
\text { ENCl } \\
\text { A } \\
\end{array}$ & $\begin{array}{l}\text { PROCE } \\
\text { SOSDE } \\
\text { CONTR } \\
\text { OL } \\
\end{array}$ & \begin{tabular}{|l|} 
INN \\
OVA \\
CIO \\
N \\
\end{tabular} & \begin{tabular}{l|l} 
PR \\
ES \\
IO \\
$\mathrm{N}$ \\
\end{tabular} & $\begin{array}{l}\text { COND } \\
\text { ICTRA } \\
\text { BAJO } \\
\end{array}$ & $\begin{array}{l}\text { REC } \\
\text { OMP } \\
\text { ENS } \\
\text { A } \\
\end{array}$ & \begin{tabular}{|c|} 
RESP \\
ONSA \\
BILIDA \\
D \\
\end{tabular} & $\begin{array}{l}\text { COR } \\
\text { DIAL } \\
\text { IDAD } \\
\end{array}$ & $\begin{array}{l}\text { IDE } \\
\text { NTI } \\
\text { DA } \\
\text { D } \\
\end{array}$ & $\begin{array}{l}\text { COM } \\
\text { UNIC } \\
\text { ACIO } \\
\text { N } \\
\end{array}$ & \begin{tabular}{|c|} 
CO \\
MIN \\
TER \\
1 \\
\end{tabular} & \begin{tabular}{|c|} 
CO \\
MUI \\
NTE \\
R2 \\
\end{tabular} & \begin{tabular}{|c|} 
COM \\
UNCI \\
NTER \\
3 \\
\end{tabular} & $\begin{array}{l}\text { AMBIE } \\
\text { NTETR } \\
\text { ABAJO } \\
\end{array}$ & \begin{tabular}{c|c} 
SATISFA \\
CCIONP \\
ERSONA \\
$\mathrm{L}$ \\
\end{tabular} & \begin{tabular}{|l|} 
VA \\
LO \\
RE \\
S \\
\end{tabular} & \begin{tabular}{|c|} 
ACTIT \\
UDUS \\
UARIO \\
S \\
\end{tabular} & $\begin{array}{l}\text { GES } \\
\text { TINN } \\
\text { INST } \\
\end{array}$ \\
\hline RESPONSABILIDAD & .027 & $.408^{*}$ & $.661^{\circ}$ & $.647^{* \prime}$ & $.566^{*}$ & $.639^{*}$ & .586 & $.694^{\prime \prime}$ & $.373^{\circ}$ & $.550^{\prime \prime}$ & $.625^{* \prime}$ & $.477^{\circ}$ & $\begin{array}{r}.24 \\
8\end{array}$ & $.327^{\circ}$ & $.587^{*}$ & 1 & $.467^{\circ}$ & $\begin{array}{l}.51 \\
0^{* *}\end{array}$ & $.529^{\prime \prime}$ & .494 & $.310^{\circ}$ & .162 & $.357^{\circ}$ & $.559^{\prime \prime}$ & \begin{tabular}{r|}
.01 \\
1
\end{tabular} & $.542^{* \prime}$ & $.593^{* *}$ \\
\hline CORDIALIDAD & $-.336^{\circ}$ & .237 & $.549^{\circ}$ & $659^{\prime \prime}$ & $.711^{\prime \prime}$ & .304 & .535 & $.473^{*}$ & .186 & $.471^{*}$ & $.435^{*}$ & .487 & $\begin{array}{r}.10 \\
9 \\
\end{array}$ & $.491^{*}$ & $.335^{\circ}$ & $.467^{* \prime}$ & 1 & \begin{tabular}{r|}
13 \\
9 \\
\end{tabular} & .235 & \begin{tabular}{|l|}
388 \\
\end{tabular} & .214 & .154 & $.561^{*}$ & $.394^{*}$ & \begin{tabular}{r|}
.00 \\
0 \\
\end{tabular} & $.376^{\circ}$ & $.415^{*}$ \\
\hline IDENTIDAD & .073 & $.390^{*}$ & .242 & .279 & .201 & $.516^{* \prime}$ & .277 & $.372^{*}$ & .099 & $.349^{*}$ & $.362^{\circ}$ & .275 & $\begin{array}{r}.04 \\
8 \\
\end{array}$ & .077 & .284 & $.510^{\circ}$ & .139 & 1 & $.541^{*}$ & .298 & .277 & .196 & .133 & .246 & $\begin{array}{r}.02 \\
6 \\
\end{array}$ & $.499^{* \prime}$ & $.440^{*+}$ \\
\hline COMUNICACION & -.238 & .251 & $.363^{*}$ & .249 & .244 & $.459^{\prime \prime}$ & .159 & .267 & $.419^{\circ}$ & $.668^{\prime \prime}$ & $.524^{* \prime}$ & $.318^{*}$ & $\begin{array}{r}.01 \\
8 \\
\end{array}$ & $.392^{*}$ & .213 & $.529^{\prime \prime}$ & .235 & $\begin{array}{c}.54 \\
1^{*} \\
\end{array}$ & 1 & 409. & .150 & .136 & .111 & .028 & $\begin{array}{r}.00 \\
0 \\
\end{array}$ & .194 & $.505^{\prime \prime}$ \\
\hline COMINTER1 & -.111 & .250 & $.349^{\circ}$ & $.391^{\circ}$ & $.340^{\circ}$ & $.370^{*}$ & 482 & $.617^{* 1}$ & $.465^{\circ}$ & $.470^{\prime \prime}$ & $.480^{\circ \prime}$ & .276 & \begin{tabular}{r|}
.09 \\
3
\end{tabular} & $.416^{\circ}$ & .112 & $.494^{\prime \prime}$ & $.388^{\circ}$ & \begin{tabular}{r|}
29 \\
8
\end{tabular} & $.409^{\circ}$ & 1 & .481. & .132 & $.650^{* \prime}$ & .242 & \begin{tabular}{|r|}
.21 \\
4 \\
\end{tabular} & $.343^{\circ}$ & $.566^{*}$ \\
\hline COMUINTER2 & .238 & $.361^{*}$ & $.320^{\circ}$ & .283 & $.385^{*}$ & $.427^{*}$ & .686 & $.520^{*}$ & $.431^{\prime \prime}$ & $.371^{*}$ & .103 & $.402^{*}$ & $\begin{array}{r}.09 \\
1 \\
\end{array}$ & .274 & .301 & $.310^{*}$ & .214 & \begin{tabular}{r|}
.27 \\
7 \\
\end{tabular} & .150 & .481 & 1 & .091 & .258 & $.382^{*}$ & $\begin{array}{r}.17 \\
4 \\
\end{array}$ & $.360^{\circ}$ & $.542^{* *}$ \\
\hline COMUNCINTER3 & -.054 & .176 & .087 & .155 & .055 & .240 & .193 & .131 & -.288 & .193 & .175 & .011 & $\begin{array}{r}.23 \\
7 \\
\end{array}$ & -.186 & .164 & 162 & .154 & $\begin{array}{r}.19 \\
6 \\
\end{array}$ & .136 & .132 & .091 & 1 & -.145 & .188 & $\begin{array}{r}.25 \\
9 \\
\end{array}$ & .051 & .183 \\
\hline AMBIENTETRABAJO & .017 & .115 & .258 & $.372^{\circ}$ & $.549^{\prime \prime}$ & .304 & .609 & $.645^{* \prime}$ & $.421^{\circ}$ & $.332^{*}$ & $.564^{\prime \prime}$ & .515 & $\begin{array}{r}.06 \\
4 \\
\end{array}$ & $.505^{\prime \prime}$ & .207 & $.357^{\circ}$ & .561 & $\begin{array}{r}.13 \\
3 \\
\end{array}$ & .111 & \begin{tabular}{|l|}
.650 \\
\end{tabular} & .258 & -.145 & 1 & $.479^{\prime \prime}$ & $\begin{array}{r}.32 \\
8^{*} \\
\end{array}$ & $.554^{\prime \prime}$ & $.522^{* \prime}$ \\
\hline SATISFACCIONPERSONAL & .287 & .261 & $.392^{\circ}$ & $.497^{\prime \prime}$ & $.565^{\prime \prime}$ & $.528^{* \prime}$ & .696 & $.632^{*}$ & .081 & $.336^{*}$ & $.334^{*}$ & $.521^{\circ}$ & $\begin{array}{r}.03 \\
9\end{array}$ & .197 & $.630^{* *}$ & $.559^{\prime \prime}$ & $.394^{\circ}$ & $\begin{array}{r}.24 \\
6 \\
\end{array}$ & .028 & .242 & $.382^{\circ}$ & .188 & $.479^{* \prime}$ & 1 & \begin{tabular}{|r|}
.14 \\
7 \\
\end{tabular} & $.548^{*}$ & $.524^{* *}$ \\
\hline VALORES & .000 & .122 & .228 & .000 & .173 & .107 & .239 & .206 & $.405^{\circ}$ & -.119 & .105 & .090 & $\begin{array}{r}.01 \\
2 \\
\end{array}$ & .284 & .086 & .011 & .000 & $\begin{array}{r}.02 \\
6 \\
\end{array}$ & .000 & .214 & .174 & -259 & $.328^{\circ}$ & .147 & 1 & .237 & .246 \\
\hline ACTITUDUSUARIOS & .155 & $.361^{*}$ & $.436^{\circ}$ & $.396^{\circ}$ & $.680^{\prime \prime}$ & $.631^{\prime \prime}$ & 675 & $.589^{* \prime}$ & .262 & $.354^{*}$ & $.605^{*}$ & $.619^{*}$ & $\begin{array}{r}.06 \\
2 \\
\end{array}$ & $.344^{\circ}$ & $.400^{\circ}$ & $.542^{\prime \prime}$ & $.376^{\circ}$ & $\begin{array}{l}.49 \\
9^{\prime \prime}\end{array}$ & .194 & 343 & $.360^{\circ}$ & .051 & $.554^{* \prime}$ & $.548^{*}$ & $\begin{array}{r}.23 \\
7\end{array}$ & 1 & $.586^{* *}$ \\
\hline GESTIONINST & .089 & $.497^{\prime \prime}$ & $.609^{\circ}$ & $.587^{* \prime}$ & $.627^{* *}$ & $.740^{\prime \prime}$ & .712 & $.695^{*}$ & $.525^{*}$ & $.629^{* \prime}$ & $.570^{* \prime}$ & .667 & $\begin{array}{r}.32 \\
2 \\
\end{array}$ & $.562^{* *}$ & $.570^{* *}$ & $.593^{* \prime}$ & $.415^{\circ}$ & \begin{tabular}{|l|}
.44 \\
0. \\
\end{tabular} & $.505^{* \prime}$ & \begin{tabular}{|l|l|}
.566 \\
\end{tabular} & $.542^{\circ}$ & .183 & $.522^{* *}$ & $.524^{* \prime}$ & \begin{tabular}{r|}
24 \\
6 \\
\end{tabular} & $.586^{* \prime}$ & 1 \\
\hline
\end{tabular}




Tabla 10. Análisis de correlación entre las variables medidas para satisfacción al cliente (alumno).

\begin{tabular}{|c|c|c|c|c|c|c|c|c|c|c|c|}
\hline \multicolumn{12}{|c|}{ Correlación } \\
\hline & Desempeño & \begin{tabular}{|c|} 
Atención \\
Directivos
\end{tabular} & $\begin{array}{c}\text { Act } \\
\text { extracurricu- } \\
\text { lares }\end{array}$ & Infraestructura & Servicios & $\begin{array}{c}\text { Desem- } \\
\text { peño } \\
\text { profe }\end{array}$ & Tutorías & Compañerismo & $\begin{array}{c}\text { Rend } \\
\text { Académi- } \\
\text { co }\end{array}$ & Practicas & Competencias \\
\hline Desempeño & 1.000 & .428 & .437 & .350 & .455 & .325 & .453 & .256 & .335 & .238 & .398 \\
\hline $\begin{array}{l}\text { Atención } \\
\text { directivos }\end{array}$ & .428 & 1.000 & .264 & 284 & 442 & 281 & .185 & .435 & .424 & 197 & .136 \\
\hline $\begin{array}{l}\text { Act } \\
\text { extracurriculares }\end{array}$ & .437 & .264 & 1.000 & .556 & .507 & .477 & .507 & 139 & .434 & .343 & .485 \\
\hline Infraestructura & .350 & .284 & .556 & 1.000 & .555 & .513 & .538 & .078 & .676 & .458 & .429 \\
\hline Servicios & .455 & .442 & .507 & .555 & 1.000 & .641 & .617 & .274 & .586 & .386 & .530 \\
\hline Desempeño profe & .325 & .281 & .477 & .513 & .641 & 1.000 & .570 & .102 & .642 & .452 & .641 \\
\hline Tutorías & .453 & .185 & .507 & .538 & .617 & .570 & 1.000 & .214 & .546 & .435 & .659 \\
\hline Compañerismo & .256 & .435 & .139 & .078 & .274 & .102 & .214 & 1.000 & .200 & .185 & .008 \\
\hline Red académico & .335 & .424 & .434 & .676 & .586 & .642 & .546 & .200 & 1.000 & .454 & .480 \\
\hline Practicas & .238 & .197 & .343 & .458 & .386 & .452 & .435 & .185 & .454 & 1.000 & .402 \\
\hline Competencias & .398 & .136 & .485 & .429 & .530 & .641 & .659 & .008 & .480 & .402 & 1.000 \\
\hline
\end{tabular}

Nota: elaboración propia con base a resultados.

\section{Conclusiones.}

Al analizar la influencia del clima organizacional en la calidad educativa basada en la Gestión Institucional, de determinó que, de los 24 indicadores medidos, solo 16 representan mayor impacto en la calidad con base a la gestión institucional. Ellos son; Identidad, Presión, Ambiente de trabajo, Visión - Misión, Recompensa, Estructura Orgánica, Competencia, Innovación, Comunicación, Objetivos - Metas, Procesos de control, Liderazgo, Responsabilidad, Cordialidad, Actitud de los usuarios y Comportamiento Organizacional.

Estos resultados coinciden con lo señalado por Chiavenato (2006), El clima organizacional está estrictamente ligado con la motivación de los miembros de la organización. Si la motivación de éstos es elevada, el clima organizacional tiende a ser alto y proporciona relaciones de satisfacción, animación, interés y colaboración entre los mismos. Sin embargo, si el clima organizacional es bajo, se caracteriza por estados de desinterés, apatía, insatisfacción y depresión. En algunos casos, puede transformarse en incomodidad, agresividad e insubordinación, situaciones en las que los miembros se enfrentan abiertamente a la organización.

Al analizar los predictores de Calidad Educativa basada en la Gestión Institucional: identidad y ambiente de trabajo representan altos valores; lo cual coincide con lo expuesto por Quevedo (2009:373), afirma: "Un buen clima organizacional, se refleja en la productividad, el compromiso organizacional, la calidad del trabajo y las relaciones interpersonales".

En el análisis de Clima organizacional y su impacto en la calidad educativa basada en la gestión institucional, se encontraron coincidencias en los predictores innovación e identidad. Es indudable que el incremento de medios personales y materiales ha de ir acompañado de una mayor capacidad para tomar iniciativas que permitan promover actuaciones innovadoras en aspectos pedagógicos, curriculares y organizativos.

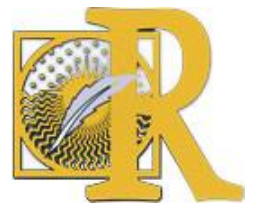

Fecha de recepción: 15-04-2020 Fecha de aceptación: 24-04-2020 
Para clima organizacional y gestión institucional, la estructura organizativa es un predictor que afecta los procesos educativos, lo cual como lo señala Martínez et al (2011:339), los procesos requieren una estructura que marque la razón de ser de la organización, no obstante, la estructura no debe verse como algo fijo, sino que debe adecuarse a las necesidades de la organización.

El clima organizacional es el resultado de los procesos que se utilizan para llevarlos a la práctica, considerando las condiciones ambientales que rodean a la empresa, área o departamento. Cada uno posee un clima propio y distinto. Los predictores más importantes es el modelo propuesto para clima organizacional, son el confort, la motivación, la identidad y la comunicación. Siendo estos aspectos señalados Litwin y Stinger (1978) como determinantes en la calidad de vida y la productividad de los integrantes y, por consiguiente, la eficacia de la organización. Asimismo, las variables de comportamiento son; las condiciones personales o particulares de los miembros, sus características psicológicas, de acuerdo a su personalidad, sus actitudes o sus capacidades que le permiten ver e interpretar la realidad de determinada manera. Por lo tanto, los aspectos psíquicos, anímicos, familiares, sociales, de educación y económicos que rodean la vida de cada individuo, intervienen en la consideración del clima organizacional de la institución.

De manera concluyente en el análisis del clima organizacional y su influencia en la calidad educativa basada en la satisfacción del alumno y en la gestión institucional, se obtuvo que las actividades extracurriculares son de gran importancia en la satisfacción del alumno y que se relacionan directamente con la innovación y la motivación.

El clima organizacional es el resultado del tipo de programas, de los procesos que se utilizan para llevarlos a la práctica, considerando las condiciones ambientales que rodean a la empresa, área o departamento. Cada uno posee un clima propio y distinto. Los predictores más importantes es el modelo propuesto para clima organizacional, son el confort, la motivación, la identidad y la comunicación. Siendo estos aspectos señalados Litwin y Stinger (1978) como determinantes en la calidad de vida y la productividad de los integrantes y por consiguiente, la eficacia de la organización. Asimismo, las variables de comportamiento son; las condiciones personales o particulares de los miembros, sus características psicológicas, de acuerdo a su personalidad, sus actitudes o sus capacidades que le permiten ver e interpretar la realidad de determinada manera. Por lo tanto, los aspectos psíquicos, anímicos, familiares, sociales, de educación y económicos que rodean la vida de cada individuo, intervienen en la consideración del clima organizacional de la institución.

En cuanto a la evaluación del desempeño de profesores para la satisfacción al cliente como análisis de la calidad educativa, la recompensa en el modelo de clima organizacional e igualmente en el modelo propuesto para gestión institucional, es un factor de especial atención en esta investigación según se aprecia en los conceptos que expresa Robbins (2004), con respecto a que las evaluaciones del desempeño sirven para varios fines, el primero, la gerencia las utiliza para tomar decisiones generales acerca del personal, puesto que brindan información sobre cuestiones importantes como los ascensos, transferencias y suspensiones; segundo, identifican las necesidades de capacitación y desarrollo; señalan las habilidades y destrezas de los empleados que son inadecuadas, pero que pueden remediarse

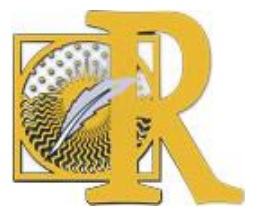

Fecha de recepción: 15-04-2020 Fecha de aceptación: 24-04-2020

Martínez Prats, G., Mapén Franco, F. J. \& Ortega Ramírez, M. E. (2021). Clima organizacional y su impacto en la calidad educativa universitaria. 
con los programas apropiados y, tercero, las evaluaciones pueden servir como criterio para validar los programas de selección capacitación.

Según el Programa de Escuelas de Calidad (2010), la gestión debe dejar a un lado los usos y costumbres que propician la rutina y el aislamiento profesional. Esto coincide con el predictor de Innovación para calidad basada en la Gestión Institucional; lo que propone es liderar procesos que aseguren los resultados; trabajar en equipo para asumir corresponsablemente las decisiones que llevan a lograr lo planeado, impulsar el involucramiento y la participación activa de los padres de familia, en la formación de sus hijos; evaluar el desempeño docente y el de los alumnos, con base en un enfoque de mejora continua. De lo que se trata es de entender, diseñar y ejecutar la planeación de la escuela y del aula de una manera totalmente renovada.

Rodríguez y Ruiz (2006) realizaron una investigación de tipo exploratoria realizada en la escuela secundaria "Experimental" de la ciudad de Xalapa, Veracruz. El objetivo fue la medición del clima organizacional que prevalecía en la institución educativa para que mediante este procedimiento se generaran propuestas de mejora. Los factores de que medir se eligieron con base a investigaciones recientes y a entrevistas, resultando los siguientes: autonomía, desempeño, estructura, apoyo, relaciones interpersonales, normatividad y trabajo en equipo.

Villareal, Pérez e Ibarra (2007) identificaron las necesidades y percepciones de los alumnos y académicos en relación con los procesos de comunicación, gestión y dirección. Con base en estos datos será posible diagnosticar el clima organizacional en los centros escolares. Las dimensiones consideradas para esta investigación fueron la dirección o el equipo directivo, gestión de trámites escolares y comunicación interpersonal.

Es de vital importancia para la Escuela Maya de estudios agropecuarios, establecer un programa de mejora en la calidad educativa, como estrategia para lograr un cambio planeado de la Escuela, centrada en los valores, actitudes, relaciones y clima organizacional, tomando como punto de partida a las personas que hacen vida en esta institución académica y que esté orientado hacia las metas, estructura o técnicas de organización. El cambio que se busca está ligado directamente a las exigencias o demandas que en la escuela intenta satisfacer al ser generadora de capital humano.

A través de este instrumento, se verificó que los agentes generadores del deterioro de las relaciones humanas y el clima organizacional detectados, de los 24 indicadores medidos, solo 16 representan estadísticamente el modelo que se propone y que generan mayor impacto en la gestión institucional. Ellos son; Identidad, Presión, Ambiente de trabajo, Visión - Misión, Recompensa, Estructura Orgánica, Competencia, Innovación, Comunicación, Objetivos - Metas, Procesos de Control, Liderazgo, responsabilidad, Cordialidad, Actitud de los usuarios y Comportamiento Organizacional.

En la satisfacción de los estudiantes hay una alta correlación entre el rendimiento académico y los predictores de Infraestructura, servicios, desempeño de profesores, desarrollo de prácticas profesionales y tutorías. Para clima organizacional, existe alta correlación entre el liderazgo y los predictores de toma de decisiones, recompensa, comunicación, confort, estructura, innovación y conflicto - cooperación. En Calidad Educativa basada en la Gestión Institucional, se presenta una alta correlación entre estructura organizativa y responsabilidad,



Fecha de recepción: 15-04-2020 Fecha de aceptación: 24-04-2020

Martínez Prats, G., Mapén Franco, F. J. \& Ortega Ramírez, M. E. (2021). Clima organizacional y su impacto en 
cordialidad; así mismo, el liderazgo tiene correlación con la aptitud de los usuarios, mientras que las estrategias están altamente correlacionadas con las condiciones de trabajo, recompensa, responsabilidad y cordialidad.

En al análisis de clima organizacional el predictor rendimiento académico se mostró altamente relacionado con la estructura organizacional, la actitud de los usuarios, motivación e identidad.

Como se puede observar es necesario considerar políticas de gestión y mejora continua en la institución educativa enfocadas al seguimiento a los indicadores de satisfacción al cliente, clima organizacional y establecer un programa de trabajo para la formación de directivos, con énfasis en la mejora de los procesos de gestión. Así como un plan de desarrollo organizacional, mediante el cual la escuela pueda evaluar las conductas, valores, creencias y actitudes de las personas en busca de enfrentar la resistencia al cambio, a través del diagnóstico, provocando un cambio en la cultura organizacional para alcanzar mejores niveles de productividad y eficiencia; que coadyuven a la mejor atención de los elementos que influyen en el clima organizacional, la Calidad Educativa basada en la Gestión Institucional y la satisfacción al cliente de la escuela maya de estudios agropecuarios.

\section{Referencias.}

- Álvarez T, C. (1994). Platiquemos de la calidad de la educación. Ed. Universidad Autónoma de Sinaloa, México.

- Brunet, L. (1987). El clima de trabajo en las organizaciones, definición, diagnóstico y consecuencias. Trillas: México.

- Chiavenato, I. (2006). El Comportamiento Organizacional. Talleres Litográficos Ingramex, S.A. de C.V., México.

- Gonçalves A. (2011). Dimensiones del clima organizacional. http://www.educadormarista.com/proyectoaprender/clima-organizacional.htm

- Hernández, R., Fernández, C. y Baptista, P. (2014). Metodología de la investigación. México: Ed. Mc Graw Hill.

- Kerlinger, F., \& Lee, H. (2002). Investigación del comportamiento. México, D. F.: McGraw Hill.

- Lafourcade, P. (1988). Calidad de la Educación. Dirección Nacional de Información, Difusión, Estadística y Tecnología Educativa del Ministerio de Educación y Justicia. Buenos Aires.

- Litwin, G.H. y Stinger, R.A. Jr. (1978). Motivación y Clima Organizacional. Harvard University.

- Martínez, M., Rodríguez, O. (2011). Caracterización del clima organizacional en instituciones de educación infantil privadas y públicas, 1-89. Universidad de la Sabana.

- Mendoza, R. (2009). El conflicto organizacional y su influencia en el desarrollo de una óptima gestión Institucional. https://proyectosytesis.blogspot.com/2009/04/el-conflictoorganizacional-y-su.html

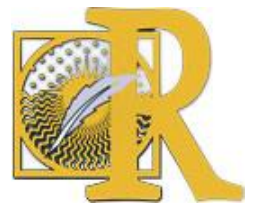

Fecha de recepción: 15-04-2020 Fecha de aceptación: 24-04-2020

Martínez Prats, G., Mapén Franco, F. J. \& Ortega Ramírez, M. E. (2021). Clima organizacional y su impacto en la calidad educativa universitaria. 
- Meneses, G, C A. (2011). La Cultura Organizacional y Las Competencias de Gestión en los Sistemas de Coordinación Educativa Artística En Madeira (Portugal). [Tesis doctoral]. Universidad de Cádiz Facultad de Ciencias del Trabajo.

- Ministerio de Salud. (2009). Metodología para el estudio del clima organizacional. Documento técnico /. Comité Técnico de Clima Organizacional, 44 p. Lima, Perú.

- Münch, L; Ángeles, E. (1990). Métodos y Técnicas de investigación. 2ª ed. 166 p. México: Trillas.

- Pallán F, C. (2014). Calidad, evaluación y acreditación en México. http://www.udual.org/CIDU/Revista/20/calidad.htm

- Quevedo B., A J (2009). Medición del Clima Organizacional. Entorno-Empresarial, México.

- Quispe De La T, D. (2014). Clima Laboral y Percepción de La Imagen Institucional en el Instituto de Educación Superior Tecnológico Público "Juan Velasco Alvarado". [Tesis Doctoral], Chile.

- Raymundo, T. L., Mapén, F., F. de J. y Martínez, P. G. (2019). Percepción de clima organizacional en una cadena de tiendas OMNICANAL en México. Revista Caribeña de Ciencias Sociales, 1-14 https://www.eumed.net/rev/caribe/2019/10/clima-organizacionalomnicanal.html

- Reddin, W. (2004). Gestión del clima organizacional en la mejora de la efectividad. Cuadernos de Management, 120. https://gref.org/nuevo/articulos/291104 2.pdf

- Robbins, S. (2004). Comportamiento Organizacional. Pearson Educación. México. 